\title{
Rising Sino-U.S. Competition in Artificial Intelligence
}

\author{
Wang You and \\ Chen Dingding
}

\begin{abstract}
Both China and the United States are international leaders in artificial intelligence (AI). Although there remains a significant gap between them in cutting-edge technologies, and they have adopted different methods of planning and implementation, both countries have been mobilizing national resources and formulating policies to promote AI development, so as to achieve a strategic advantage over the other, especially against the backdrop of ever more intense and complicated strategic competition between them in recent years. As an epitome of their changing relationship, Sino-U.S. competition in AI development is manifested in economic, political, security, technological and other fields. It is expected that artificial intelligence will become an even more important field of competition between China and the United States, and that the trends of
\end{abstract}

Wang You is an MA candidate at the School of International Relations/Institute of Overseas Chinese Studies, Jinan University. She can be reached at 51230683@qq.com. Chen Dingding is Professor at the School of International Relations/Institute of Overseas Chinese Studies, Jinan University. He can be reached at ddchen@jnu.edu.cn. Their mailing address is: School of International Relations, Jinan University, 601 Huangpu Road West, Guangzhou 510632, China.

(c) 2018 World Century Publishing Corporation and Shanghai Institutes for International Studies China Quarterly of International Strategic Studies, Vol. 4, No. 2, 241-258

DOI: $10.1142 / S 2377740018500148$

This is an Open Access article, copyright owned by the SIIS and WCPC. The article is distributed under the Creative Commons Attribution 4.0 (CC BY-NC) Licence. Further distribution of this work is permitted, provided the original work is properly cited and for non-commercial purposes. 
AI development and competition will to some extent determine the future dynamics of their bilateral relations.

Keywords: Artificial intelligence (AI); Sino-U.S. relations; strategic competition; power politics.

\begin{abstract}
As the shifting balance of power between the United States and China threatens to fundamentally change the post-World War II international order, U.S. perceptions of China have turned ever more negative in recent years. ${ }^{1}$ Many scholars believe that China and the United States have entered an era of strategic competition, and that one of the key fields of competition is science and technology. ${ }^{2}$ In the development of artificial intelligence (AI), while the United States enjoys a "first-mover advantage," China is catching up at such a pace that some U.S. experts see an "arms race" ensuing between them. ${ }^{3}$

Apparently, the ongoing strategic competition between China and the United States drives the dynamics of their competition in artificial intelligence, which, in turn, affects their interaction in the political, economic, and security arenas, and to a certain degree, defines the balance of power between them. This paper aims to perform a detailed analysis into the AI development and related policies in China and the United States, so as to provide a better understanding of the trends in Sino-U.S. relations as well as the impact of AI development on future international relations.
\end{abstract}

\title{
International Relations in the Age of Artificial Intelligence
}

By definition, artificial intelligence is a diverse technology based on big data and machine learning, the purpose of which is to promote greater integration of machine intelligence with social production and into daily life. Since its inception in the mid-20th century, artificial intelligence has been

${ }^{1}$ Da Wei, “The 'Trump Shock' and the Evolution of U.S. Strategy Toward China," World Economics and Politics, No. 5 (2017), pp. 21-37.

${ }^{2}$ For example, see Wang Tao and Zhao Yanyun, "Structural Changes in International Competitiveness of China and the United States," Industrial Economic Review, No. 4 (2017), pp. 59-67.

${ }^{3}$ Michelle Fox, "US in 'Arms Race' with China for A.I. Tech and Talent, says Billionaire Tech Investor," CNBC, September 12, 2017, https://www.cnbc.com/2017/09/12/us-chinacompete-for-a-i-tech-and-talent-says-billionaire-investor.html. 
affecting social and economic development in a profound and comprehensive way. Today, it has become the driver of a new industrial revolution, a new arena for international competition, and a new engine of economic growth. ${ }^{4}$ According to a report by $\mathrm{PwC}$, the London-based multinational professional services network, global GDP will be US\$15.7 trillion, or 14 percent, higher in 2030 as a result of AI development, and labor productivity improvements are expected to account for over half of all economic gains from AI over the period 2016-2030. ${ }^{5}$

With the rapid progress of AI technologies, countries around the world have begun to attach great importance to AI development and the related social issues it may bring about. Japan, Russia, and the European Union (EU) are all crafting bold plans for AI development, mainly as a means to spur economic growth and social progress. On October 15, 2017, the British government released an academic report entitled Growing the Artificial Intelligence Industry in the $U K$, which aims to make the country "the best place in the world for businesses developing and deploying AI to start, grow and thrive, to realize all the benefits the technology offers." The report estimated that AI development could add an additional US $\$ 814$ billion to the British economy by 2035 and increase the annual growth rate of gross value added (GVA) from 2.5 to 3.9 percent. $^{6}$

AI has become a main field for great power competition. In January 2016, Japan put forward a blueprint for the future society called a "Super Smart Society" to develop Japanese information technology, artificial intelligence and robotics. ${ }^{7}$

${ }^{4} \mathrm{Mao} \mathrm{Li}$, “Zhiku baogao jianyi jiada rengongzhineng lingyu rencaiyinjin [Think-tank Report Recommends Enhancing Introduction of Talents in Artificial Intelligence]," Chinese Social Sciences Net, December 5, 2017, http://ex.cssn.cn/zk/zk_jsxx/zk_zx/201712/t2017 1205_3769727.shtml.

${ }^{5}$ Anand S. Rao and Gerard Verweij, "Sizing the Prize: What's the Real Value of AI for Your Business and How Can You Capitalise?," PricewaterhouseCoopers, https://www.pwc. com/gx/en/issues/analytics/assets/pwc-ai-analysis-sizing-the-prize-report.pdf.

${ }^{6}$ Dame Wendy Hall and Jérôme Pesenti, “Growing the Artificial Intelligence Industry in the UK," October 15, 2017, https://www.gov.uk/government/publications/growing-the-artificial-intelligence-industry-in-the-uk, p. 2.

${ }^{7}$ Zhao Gang, "Rengongzhineng daguo zhanlue [Artificial Intelligence Strategies of Great Powers]," Globe, No. 7 (2017). 
The Russian government quickly followed suit by announcing the "Russian Digital Economy Plan" on July 31, 2017, which lists the digital technologies that Russia will prioritize in the future, including big data, neural network and artificial intelligence, among others. ${ }^{8}$ In March 2018, Russia's Foundation for Advanced Studies published its proposals for the Ministry of Defense to standardize AI development along four lines: image recognition, speech recognition, control of autonomous military systems, and information support for weapons' life cycle. ${ }^{9}$ Similarly, on April 10, 2018, 24 EU countries pledged to band together to form a "European approach" to AI by putting necessary public research funds into AI development. Accordingly, they are taking active measures to earmark public funds and encourage companies to invest in technologies like robotics and medical applications that process huge amounts of data. ${ }^{10}$

Clearly, many countries including China regard AI as a major element of their military power and believe that it will become a main field for competition among countries. ${ }^{11}$ As the founder of AI technology, the United States had begun to apply elements of AI to its military platforms more than a decade before. The Defense Advanced Research Projects Agency (DARPA) launched the "Deep Green Project" in 2007, the purpose of which was to develop a decision-making support system for U.S. Army commanders by using computers to efficiently and accurately

8"Eluosi chutai shuzijingji guihua [Russia Announces Digital Economy Planning]," Science and Technology Strategic Advisory Institute, Chinese Academy of Sciences, October 16, 2017, http://www.casisd.cn/zkcg/ydkb/kjzcyzxkb/2017/201710/201710/t2017 1016_4873736.html.

9Samuel Bendett, "In AI, Russia is Hustling to Catch Up," Defense One, April 4, 2018, https://www.defenseone.com/ideas/2018/04/russia-races-forward-ai-development/147178/.

${ }^{10}$ Catherine Stupp, “Twenty-four EU Countries Sign Artificial Intelligence Pact in Bid to Compete with US and China," Euractive, April 11, 2018, https://www.euractiv.com/section/ digital/news/twenty-four-eu-countries-sign-artificial-intelligence-pact-in-bid-to-competewith-us-china/.

${ }^{11}$ Xiao Jing and Shi Haiming, "Rengongzhineng riyichengwei daguo junshijiaoliang de kejiqianyan [AI Increasingly Becomes the Technological Frontier for Military Competition among Major Powers], Globalview, September 12, 2017, http://www.globalview.cn/html/ military/info_20226.html. 
predict possible future scenarios based on a full analysis of the situation on hand. ${ }^{12}$

Indeed, AI development has been widely recognized as a manifestation of a country's comprehensive power. As national competitiveness largely depends on the capacity of a country's industry to innovate and upgrade, it is necessary for countries to achieve competitive advantage through continuing innovation, particularly in the field of AI. Against this backdrop, both China and the United States have formulated respective long-term strategies to boost AI development and to enhance their position in the competition for leadership in the field.

\section{Capability Gaps Between China and the United States}

Despite China's strenuous efforts to promote AI development, there remain huge gaps in AI capabilities between China and the United States - not only in science and technology, but also in related industries and talents. The United States is far ahead of China in AI theory and microchips, while China still lacks the depth of basic research and originality. Besides, the United States is superior to China in industrial structure and distribution as well as business environment. It also enjoys significant advantages in AI-related talents.

The United States is undoubtedly the world leader in cutting-edge AI technology. Its research in AI has not only enjoyed an early start and solid foundation, but also benefited from various AI-focused economic practices. AI companies had begun springing up in the United States since 1991, while the first Chinese AI company was set up only in 1996. In fact, most of the Chinese AI companies were established only during the past few years, with 20.8 percent of AI start-ups founded in 2014, 34.5 percent in 2015, and 16.7 percent in $2016 .{ }^{13}$ Today, most of the world's technological giants, such as Google, Amazon, IBM and Microsoft, are located in the United States, and they have gathered some of the best AI teams in the world, making the

12“DARPA's Commander's Aid: From OODA to Deep Green,” Defense Industry Daily, June 3, 2008, https://www.defenseindustrydaily.com/darpa-from-ooda-to-deep-green-03497/.

13“2017 zhongguo rengongzhineng chanye shendu jiexi baogao [2017 Analytical Report on China's Artificial Intelligence Industry]," Sohu. com, December 5, 2017, http://www.sohu. com/a/208492697_730713. 
United States a strong leader in AI research and development (R\&D). Moreover, since the 1990s, the U.S. military has gained an absolute advantage in information warfare.

The U.S. superiority over China in talent reserve, innovation systems, and related hardware development is first and foremost manifested in its leading position in developing computer algorithms. ${ }^{14}$ Furthermore, China's semiconductor industry lags far beThe U.S. enjoys vast advantages over China in AI development. hind in making high-end electronic processors. ${ }^{15}$ As David Kanter, head of Real World Insights, observes, "Most AI-focused chips are developed by U.S. companies, and it will be a long slog for China to catch up." ${ }^{16}$ Experts believe that for China to achieve its goal of becoming a global innovation center in this field by 2030, it must first solve the problem of a serious lack in fundamental theory. ${ }^{17}$

The Chinese government has expended much effort to encourage AI $R \& D$, so as to narrow the gap with the United States. At present, more journal articles on deep learning is published in China each year than in the United States, while AI-related patent submissions from Chinese researchers have nearly doubled over the past few years. ${ }^{18}$ In 2016, the United States ranked first in the world with a total of 26,891 applications for

14"Zhongmei liangguo rengongzhineng chanye fazhan quanmian jiedu [A Comparison of Artificial Intelligence Strategies and Policies between China and the United States]," Tencent Research Institute, July 26, 2017, http://www.tisi.org/Public/Uploads/file/20170802/ 20170802172414_51007.pdf.

${ }^{15}$ Reinhardt Krause, "In AI Technology Race, U.S. Chips May be Ace-In-The-Hole Vs. China," Investor's Business Daily, November 27, 2017, https://www.investors.com/news/ technology/ai-technology-u-s-chip-stocks-vs-china/.

${ }^{16}$ Ibid.

${ }^{17}$ Liao Shumin, "China Can Compete Globally in AI But Lacks Strength in Systems and Theory, Turing Award Winner Says," Yicai Global, September 22, 2017, https://www.yicaiglobal.com/news/china-can-compete-globally-ai-lacks-strength-systems-and-theory-turingaward-winner-says.

${ }^{18}$ Louise Lucas, "China Seeks Hegemony in the Global Artificial Intelligence Industry," Financial Times, October 18, 2017, http://www.ftchinese.com/story/001074698/en?ccode=LanguageSwitch\&archive. 
AI patents, compared with 15,745 applications in China. ${ }^{19}$ Yet in 2017, China had four times as many AI-related patent applications as the previous year, far surpassing the number of the United States. ${ }^{20}$

Nevertheless, there still exist huge gaps between China and the United States in industrial scale, product quality and financial support of AI development. Nothing is more evident of this than the number of AI-related enterprises in both countries. As of 2017, there were nearly 2,800 AI companies in the United States, accounting for 41 percent of the world's total, but only 1,500 AI companies in China. ${ }^{21}$ However, China's AI industry is catching up rapidly. According to global consulting firm, Ernest \& Young, the output of China's AI industry reached 15 billion Renminbi (RMB) in 2017, an increase of 50 percent over the previous year. ${ }^{22}$ Furthermore, the size of China's AI-related core industry exceeded 70 billion RMB in 2017. It is estimated that the scale of the $\mathrm{AI}$ industry in China will exceed 160 billion $\mathrm{RMB}$, with an annual growth rate of 26.2 percent by $2020 .^{23}$ With strong policy support and growing investment from the financial market, the scale of China's AI industry is rapidly catching up with that of the United States.

With regard to the industrial distribution system, the U.S. advantage over China is also apparent, especially for the basic, high-grade and application industries. ${ }^{24}$ While China has the requisite database scale and algorithm applications, China's AI industry suffers from a lack of sufficient

19“Wuzhen zhishu — 2017nian quanqiu rengongzhineng fazhan baogao [Wuzhen Index: Global Artificial Intelligence Development Report]," Wuzhen Institute, August 2017, http:// sike.news.cn/hot/pdf/25.pdf.

${ }^{20}$ Ralph Jennings, "China Leads the U.S. in Patent Applications for Blockchain and Artificial Intelligence," Forbes, May 17, 2018, https://www.forbes.com/sites/ralphjennings/ 2018/05/17/how-china-pulled-ahead-of-the-u-s-in-patent-applications-for-new-technology/ \#4bada2a16048.

21 "A Comparison of Artificial Intelligence Strategies and Policies between China and the United States."

${ }^{22}$ Shi Jing, "The AI Sector's Manpower Crunch," China Daily, June 2, 2018, http://www. chinadaily.com.cn/a/201806/02/WS5b11977ea31001b82571dc75.html.

23"Rengongzhineng chanye kuaisu fazhan, 2020nian guimo jiang tupo 1600yi [Artificial Intelligence Industry is Developing Rapidly and Will Break 160 Billion in 2020]," China News, March 23, 2018, http://www.chinanews.com/cj/2018/03-23/8474110.shtml.

24 "A Comparison of Artificial Intelligence Strategies and Policies between China and the United States." 
computing power, which is closely related to the development of processing chips. The weakness of China's chip industry has seriously affected the development of its AI industry. According to Chinese statistics, the United States boasts 33 chip firms with a total investment of 30 billion RMB, while China has only 13 chip firms with a total investment of 1.3 billion RMB. ${ }^{25}$ As a result, China is lagging behind the United States in core technological competency.

In recent years, there has been an explosion of investment in artificial intelligence around the world, and China and the United States are the world's largest markets for investment in the AI industry. In 2017, Chinese AI start-ups for the first time received more investment than their American counterparts. ${ }^{26}$ Yet some experts think the Chinese AI market lacks highquality projects, and that the high increase rate in investment may not generate due profits. ${ }^{27}$

China has always faced a shortage of technological talents. According to a survey, there are about 1.9 million AI engineers worldwide, among whom one million are working in the United States, and only 50,000 work in China. ${ }^{28}$ Some 1,078 AI companies in the United States hire 78,700 employees, while China's 592 AI companies hire only 39,200 employees. ${ }^{29}$ Also, there are much more "top" scholars and researchers in the United States than in China. Of the 367 universities worldwide that have set up a major in artificial intelligence, 168

${ }^{25}$ Tyler Xie, "What are the Drivers of Artificial Intelligence Industry, China vs. U.S.?," Medium, September 26, 2017, https://medium.com/the-harbinger-china/what-are-the-drivers-of-artificial-intelligence-industry-china-vs-u-s-f94ecc4ea0db.

${ }^{26}$ Lu Yongkang, "Mei zuixin baogao: zhongguo rengongzhineng chuangqi rongjie shouchao meiguo wei quanqiu diyi [China First Surpasses the United States in Funding for Artificial Intelligence Start-ups in the World]," Qudong.com, February 24, 2018, http://www.qudong. com/2018/0224/468351.shtml.

${ }^{27}$ Tyler Xie, "What are the Drivers of Artificial Intelligence Industry, China vs. U.S.?"

${ }^{28}$ Meghan Han, “China Prepares for AI Talent Shortage," Synced, April 12, 2018, https://syncedreview.com/2018/04/12/china-prepares-for-ai-talent-shortage/.

29"A Comparison of Artificial Intelligence Strategies and Policies between China and the United States." 
are in the United States, while only a few Chinese universities list AI as a major. ${ }^{30}$ Nearly all the best computer science/artificial intelligence colleges of the world - Carnegie Mellon, Massachusetts Institute of Technology, Stanford, and University of California at Berkeley, for instance - are located in the United States. ${ }^{31}$ Even with relatively higher pay for AI developers, the lack of talents will remain a bottleneck for the development of China's AI industry.

\section{AI Strategies of China and the United States}

Both China and the United States are determined to seize the strategic opportunity for the development of artificial intelligence, which has emerged as a national priority and is pursued at the highest level of government. Both governments have made clear the importance of artificial intelligence from the aspects of economic development, national security, and international competition. ${ }^{32}$

In October 2016, the White House Office of Science and Technology Policy (OSTP) released two reports entitled Preparing for the Future of Artificial Intelligence ${ }^{33}$ and Networking and Information Technology Research and Development Subcommittee, ${ }^{34}$ respectively. The two reports suggest that the U.S. government "seize the opportunity" for AI development and that the U.S. national strategy should aim to foster innovation across the industry and academia. Unlike the extensive reversal of Obama-era policies in other areas, the Trump administration announced in the National Security

${ }^{30}$ Ibid.

31 “Best Grad Schools Ranked in 2018," U.S. News and World Report, https://www. usnews.com/best-graduate-schools/top-science-schools/artificial-intelligence-rankings.

${ }^{32}$ Tom Simonite, “Defense Secretary James Mattis Envies Silicon Valley's AI Ascent," Wired, August 11, 2017, https://www.wired.com/story/james-mattis-artificial-intelligence$\operatorname{diux} /$.

${ }^{33}$ Preparing for the Future of Artificial Intelligence (Washington, D.C.: Executive Office of the President/National Science and Technology Council/Committee on Technology, October 2016), https://obamawhitehouse.archives.gov/sites/default/files/whitehouse_files/microsites/ ostp/NSTC/preparing_for_the_future_of_ai.pdf.

${ }^{34}$ Networking and Information Technology Research and Development Subcommittee (Washington, D.C.: National Science and Technology Council, October 2016), https://www. nitrd.gov/PUBS/national_ai_rd_strategic_plan.pdf. 
Strategy Report in December 2017 that "the United States will prioritize emerging technologies critical to economic growth and security, such as data science, encryption, autonomous technologies, gene editing, new materials, nanotechnology, advanced computing technologies, and artificial intelligence." ${ }^{\prime 35}$ Defense Secretary James Mattis further added that the United States would invest in new technologies such as nuclear deterrence, missile defense and artificial intelligence to help prepare the armed forces. ${ }^{36}$

The Chinese government also attaches great importance to AI R\&D, emphasizing that artificial intelligence has become a new focus of international competition. As stressed in its "A New Generation of Artificial Intelligence Development Plan" released on July 20, 2017, "Artificial intelligence is thought to be the strategic technology leading the future," and thus more efforts should be taken to "build China's first-mover advantage in artificial intelligence development." ${ }^{\prime 37}$

However, there are many differences in AI development strategies between them, showing the traditional differences between the industrial policies of both countries. In general, the United States encourages the full participation of all actors including businesses, academics, policy makers, consumer organizations, and other representatives of the civil society; China, in contrast, places AI development within its longstanding tradition of centrally-planned engineering under its Next Generation Artificial Intelligence Plan. ${ }^{38}$ In promoting AI R\&D, the U.S. government is also making effort to prevent the negative social effects brought about by AI development, whereas China emphasizes the prosperity of AI

${ }^{35}$ National Security Strategy of the United States of America (Washington, D.C.: The White House, December 2017), https://www.whitehouse.gov/wp-content/uploads/2017/12/NSSFinal-12-18-2017-0905.pdf.

${ }^{36}$ Sara Shayanian, “Mattis: U.S. Military's Competitive Edge Has 'Eroded,"' United Press International, February 6, 2018, https:/www.upi.com/Top_News/US/2018/02/06/Mattis-US-militarys-competitive-edge-has-eroded/9761517931706/.

37 "Guowuyuan guanyu yinfa xinyidai rengongzhineng fazhanguihua de tongzhi [Notice of the State Council on Issuing a New Generation Artificial Intelligence Development Plan]," State Council of the People's Republic of China, July 20, 2017, http://www.gov.cn/zhengce/ content/2017-07/20/content_5211996.htm.

${ }^{38}$ Matt Sheehan, "How China's Massive AI Plan Actually Works," Asia Dialogue, April 11, 2018, http://theasiadialogue.com/2018/04/11/how-chinas-massive-ai-plan-actuallyworks/. 
technology and industry as well as the cooperation between government and enterprises.

To be more specific, the U.S. government was involved in AI R\&D much earlier than its Chinese counterpart. As early as 2013, the U.S. government began providing US\$2.2 billion for R\&D of advanced manufacturing focusing on innovative manufacturing processes, advanced industrial materials, and robotics, and it has encouraged greater federal collaboration with universities and related industries. ${ }^{39}$ In comparison, China announced its AI development goals in July 2017, which aims to "keep pace with AI technology by 2020, make major breakthroughs by 2025, and lead the world in AI by 2030." 40

There are also many differences between China and the United States in the policy-making process regarding AI R\&D. The formulation of the U.S. AI strategy and policies is heavily influenced by political factions, interest groups, enterprises, and research institutions, while a "strong government" is expected to be key to China's AI policy. Like in other areas of industrial development, the Chinese government plays a major role in AI

\section{AI R\&D in the U.S.} may slow down due to reduced federal support under President Trump. R\&D by deliberating a national AI strategy, making related policies and, most importantly, committing to massive investment to promote AI development.

It is worth noting that in spite of its continued strategic attention to AI development, the Trump administration has not given as much federal support to AI R\&D as the Obama administration did. The 2017 federal budget proposed by President Trump reduces the National Science Foundation's spending on intelligent systems by 10 percent, to about US $\$ 175$ million; these cuts would essentially shift more R\&D tasks to private

39 “Press Release: Innovation for America's Economy, America's Energy, and American Skills: The FY 2013 Science and Technology R\&D Budget," The White House, February 13, 2012, https://obamawhitehouse.archives.gov/the-press-office/2015/11/23/press-release-innovation-americas-economy-americas-energy-and-american.

40 "Notice of the State Council on Issuing a New Generation Artificial Intelligence Development Plan." 
companies like Google and Facebook. ${ }^{41}$ Up till now, the White House Office of Science and Technology Policy still has a large number of vacancies to be filled. Besides, with the recent immigration clampdown, the United States might soon find it difficult to attract and retain technological experts from around the world in AI R\&D. ${ }^{42}$

China and the United States differ in approaches of strategic mobilization on AI R\&D as well. While trying to maintain its lead in AI technology, the United States tends to highlight the ethical, legal, and social elements of AI development, and thus endeavors to foster appropriate governance models and responses. There are at least 16 independent economy-related departments involved in artificial intelligence in the U.S. government regulating the application of AI technology, such as the use of AI technologies in medical equipment and treatment or as a financial tool, and the commercialization of drones. ${ }^{43}$ The U.S. government also emphasizes the participation of multiple actors - enterprises, research institutions, and social organizations, etc. - in its AI strategy, although AI companies in the United States are often reluctant to invest in national security applications. For example, when Google acquired DeepMind, the world leader in AI R\&D, the latter assured that it would not allow its technology to be used in military applications. ${ }^{44}$

In comparison, China adopts a top-down approach in industrial distribution and capital flow for AI R\&D, and focuses on making policies to facilitate the rapid growth of the AI industry. The government has been emphasizing "two-way transformation and application of military-civilian

${ }^{41}$ Paul Meng and John Markoff, “Is China Outsmarting America in A.I.?," The New York Times, May 27, 2017, https://cn.nytimes.com/china/20170527/china-us-ai-artificialintelligence/?action $=$ click\&contentCollection $=$ Technology\&module $=$ Translations\&region $=$ Header\&version $=\mathrm{zh}-\mathrm{CN} \& \mathrm{ref}=$ en-US\&pgtype $=$ article.

${ }^{42}$ Vikram Barhat, "China is Determined to Steal A.I. Crown from US and Nothing, Not Even a Trade War, Will Stop It," CNBC, May 4, 2018, https://www.cnbc.com/2018/05/04/ china-aims-to-steal-us-a-i-crown-and-not-even-trade-war-will-stop-it.html.

43"One Hundred Year Study on Artificial Intelligence (AI100)," Stanford University, August 1, 2016, https://ai100.stanford.edu.

${ }^{44}$ Sam Shead, “The CEO of Google's $£ 400$ Million AI Startup is Going to Meet with Tech Leaders to Discuss Ethics," Business Insider, November 5, 2015, http://www.businessinsider. com/the-ceo-of-googles-400-million-ai-startup-is-going-to-meet-with-tech-leaders-2015-11? $\mathrm{r}=\mathrm{UK} \& \mathrm{IR}=\mathrm{T}$. 
technological achievements, joint construction, and sharing of innovative resources between the military and the people." ${ }^{45}$ Many policies have been issued in recent years to guide AI R\&D, such as the "Guidance on Active Promotion of Internet Plus," "Development Plans of the New Generation Artificial Intelligence," "Promoting the Development of New Generation Artificial Intelligence Industry," and the "Three-Year Action Plan for the Development of a New Generation of Artificial Intelligence Industries (2018-2020)." In addition, 12 Chinese provinces including Guangdong and Zhejiang have launched their own plans for AI development. ${ }^{46}$ It is hard to say which country is going to "win" in the competition for AI leadership, but China is indeed catching up rapidly with the United States with this top-down approach.

\section{A New Battlefield for China and the United States}

The competition between China and the United States in the field of artificial intelligence is gradually heating up. Ian Bremmer, founder and president of the Eurasia Group, believes that "China is the better bet to win if the decisive factor is depth of commitment to a single goal and the depth of pockets in pursuing it. The one certainty here is that Washington - and the representative democracy and free-market capitalism it champions is not in the race." ${ }^{47}$ To prevent this from happening, the U.S. government has formulated a series of policies to contain AI development in China, further aggravating the strategic competition between the two great powers - although in the eyes of James Lewis, senior fellow at the Center for Strategic and International Studies (CSIS), the reason why AI competition between China and the United States is on the rise is that "China seems to

45 “Notice of the State Council on Issuing a New Generation Artificial Intelligence Development Plan."

46"Summary and Interpretation of Artificial Intelligence Industry Policies Across China in 2018," China Business Intelligence, January 12, 2018, http://m.askci.com/news/finance/ 20180112/174941115929.shtml.

${ }^{47}$ Ian Bremmer, "How China's Economy is Poised to Win the Future," Time, November 2, 2017, http://time.com/magazine/south-pacific/5007633/november-13th-2017-vol-190-no20-asia-europe-middle-east-and-africa-south-pacific/. 
think it's a race and America doesn't." ${ }^{48}$ Now that China is determined to catch up with the United States, one can expect even more intense competition between both countries in the years to come.

First of all, the U.S. government may increase policy and financial support for AI development, including deliberating a clear plan for international competition. ${ }^{49}$ As Gordon England, former Secretary of the Navy and Deputy Secretary of Defense, warns, "Other nations understand this [AI competition] all too well, and they are accelerating their research programs while we seemingly stumble and falter. We do so at our peril. ${ }^{\prime 50}$ In particular, there is a need to keep on attracting the world's top talents. ${ }^{51}$ In fact, many experts have called on the U.S. government to give more support to AI companies, such as funds and industrial policies, in response to the rapid AI development of China and other countries.

Second, the U.S. government will put more limits on Chinese investment in U.S. AI companies. It is widely believed in Washington, D.C. that Chinese firms are circumventing U.S. oversight and gaining access to sensitive AI technology with potential military applications by buying stakes in American companies. Consequently, in 2015, the

The U.S. targets

China as a key competitor in AI development.

Obama administration barred Intel, Nvidia and Advanced Micro Devices (AMD) from selling high-end supercomputer chips to China over concerns that they would be channeled to military uses; and in September 2017, the Trump administration blocked the sale of Lattice

${ }^{48}$ Mozur and Markoff, "Is China Outsmarting America in A.I.?"

${ }^{49}$ Zachary Cohen, "US Risks Losing Artificial Intelligence Arms Race to China and Russia," CNN, November 29, 2017, http://edition.cnn.com/2017/11/29/politics/us-militaryartificial-intelligence-russia-china/index.html.

${ }^{50}$ Gordon England, "US is Losing Ground on Technology Superiority," The Hill, December 6, 2017, http://thehill.com/opinion/technology/363621-us-is-losing-ground-ontechnology-superiority.

${ }^{51}$ Elsa B. Kania, “Emerging Technology Could Make China the World's Next Innovation Superpower," The Hill, November 6, 2017, http://thehill.com/opinion/technology/ 358802-emerging-technology-could-make-china-the-worlds-next-innovation-superpower. 
Semiconductor (LSCC) to a Chinese-backed investor, for Lattice owns programmable software technology that offers an alternative way of building AI chips. In the meantime, U.S. companies and research institutions are going all out to attract AI talents from China. ${ }^{52}$ Thus, the race between China and the United States for AI leadership will largely manifest in the competition for talents.

Third, the U.S. government will make more effort to draw up AI technical standards, as standardization not only adds competitiveness to U.S. companies, but is vital to set the pace of international competition as well. ${ }^{53}$ The U.S. government has tried hard to establish a surveillance system for international AI technology and keep its cybersecurity protection mechanism up to date. ${ }^{54}$ Thus, it is highlighted in the White House 2016 report Preparing for the Future of Artificial Intelligence that there is an urgent need to monitor the development of AI technology in other countries, and that a list of AI hotspots that require international participation and supervision should be compiled. ${ }^{55}$

Technological innovation is a decisive element of national power and competitiveness, which is an important lesson China has learned from decades of international competition. Since the United States regards China as a key competitor in AI development, China seems to have no other way but to face up to the challenge and speed up its AI R\&D. China has a clear understanding of its capacity gap with the United States in AI technology. As the White Paper on Standardization of Artificial Intelligence issued by the Chinese government points out, "The overall development level of artificial intelligence in China still lags behind the developed countries." ${ }^{56}$ It can be

${ }^{52}$ David Cyranoski, “China Enters the Battle for AI Talent,” Nature, January 17, 2018, https://www.nature.com/articles/d41586-018-00604-6.

${ }^{53}$ Will Knight, "China Wants to Shape the Global Future of Artificial Intelligence," MIT Technology Review, March 16, 2018, https:/www.technologyreview.com/s/610546/chinawants-to-shape-the-global-future-of-artificial-intelligence/.

54 “The President in Conversation with MIT's Joi Ito and WIRED's Scott Dadich," Wired, August 24, 2016, https://www.wired.com/2016/10/president-obama-mit-joi-ito-interview/.

${ }^{55}$ Preparing for the Future of Artificial Intelligence.

${ }^{56}$ CESI, Rengongzhineng biaozhunhua baipishu 2018ban [White Paper on Standardization of Artificial Intelligence, 2018 (Beijing: China Electronic Standardization Institute, January 2018). 
expected that the primary goal of China in AI development is to catch up with the United States in AI technology.

Toward this end, the Chinese government has issued a number of policies to attract AI talents from around the world, especially Chinese graduates of AI-related majors from universities and research institutions in developed countries. According to LinkedIn's Global AI Talent report, the average annual growth rate of AI graduates returning to China is about 14 percent, and the growth rate of personnel with overseas working backgrounds in the AI field is about 10 percent. ${ }^{57}$ Meanwhile, the Chinese government is setting up barriers for entry of foreign AI companies while limiting the flow of data across borders. ${ }^{58}$ With the tightening of immigration policy and work visa policy under the Trump administration, China is hopeful to attract more AI talents to work in Chinese companies and research institutions.

At the same time, there is another perspective that AI is not necessarily a new "battlefield" between China and the United States. As Elsa B. Kania observes, "artificial intelligence is still a field of cooperation and competition between China and the United States." ${ }^{59}$ Many researchers even believe that the interaction between China and the United States in AI is more cooperative than competitive. ${ }^{60}$ Indeed, some studies find that U.S. technology giants are leading the world in basic technology, while Chinese companies have strong technological capabilities in such subdivided areas as image recognition, speech recognition, and autonomous driving. In other words, AI technologies of China and the United States can be complementary.

Why, then, has the AI race become a new dimension of Sino-U.S. competition? On one hand, because major breakthroughs in AI technology

57“LinkedIn Quanqiu AI lingyu rencai baogao, jieshi quanqiu AI rencai tupu [LinkedIn's Global AI Talent Report Reveals the Map of Global AI Talents]," Sohu. com, July 6, 2017, www.sohu.com/a/154923010473283.

58“Global AI Hub? The V Factors Powering China's Rise," Vertex, July 2017, http:// simple-rules.com/vertex.pdf.

${ }^{59}$ Ibid.

${ }^{60} \mathrm{Niu}$ Shuai and Li Zheng, "Artificial Intelligence: A New Frontier of Cooperation," China-US Focus, August 29, 2017, http://cn.chinausfocus.com/political-social-development/ 20170829/20362.html. 
and application can substantially change the balance of military and economic power between both countries, their significance for national security and development has been on the rise, making the AI race more like a zerosum game. On the other hand, due to the series of confrontational policies of the Trump administration toward China, in particular the ongoing trade disputes, the overall atmosphere of Sino-U.S. relations has turned ever more gloomy, paving the way for more intense competition between both countries in nearly all arenas. In this light, artificial intelligence, as a strategic and cutting-edge technology, is becoming a main battlefield of competition between China and the United States.

The race for $\mathrm{AI}$

development has

become a main field

of Sino-U.S.

competition.
The Sino-U.S. AI race is quite extensive, covering quantum science, gene science, and space science, among other disciplines. However, the AI race is of special significance compared with the competition of science and technology in other fields. First, AI technology can be applied to national defense, economic development and other areas that are of vital importance to a country. Second, compared with other high-end and new technologies, AI bears the characteristic of "self-learning," thus a country's "first-mover advantage" can hardly be superseded - the more advanced one's AI technology, the faster its technological innovation and upgradation. Third, the AI race is a kind of strategic competition that needs strategic assessment, decisionmaking, and mobilization of resources of the whole country. Therefore, the competition between China and the United States in AI development may escalate the Sino-U.S. competition in military, economic, trade, technological and other fields.

\section{Conclusion}

Artificial intelligence is a new engine of economic development, a new focus of international competition, and a new opportunity for social construction. The Chinese government believes that AI development has the significance of comprehensively supporting the promotion of science and technology, economy, social development, and national security, a key step 
toward becoming a global power in science and technology. ${ }^{61}$ Although there remains a huge gap between China and the United States in terms of AI technology, industry, and talents, China has taken the initiative to promote AI technology and industrial applications, so as to catch up with the United States. Against this backdrop, the United States has positioned China as a key competitor in AI development, and introduced a number of policies and measures to strengthen its own AI R\&D while trying to impede China's AI development.

With the increasingly intense strategic competition between China and the United States in recent years, both countries are likely to race against each other with even stronger measures in $\mathrm{AI} R \& D$, such as more policy and financial support for AI industries, and more stringent laws and regulations for entry of the other's investment in related businesses. In the past, China has been lagging behind in AI development partly due to its relatively weak scientific and industrial bases as well as its centralized way of mobilizing AI R\&D. Now that the Chinese government has adopted a facilitating strategy for the participation of the academic, business and other social sectors, together with more effective measures to attract AI talents to work in Chinese AI R\&D, China has a chance to gain a stronger position in this decisive race, which will to some extent determine the future dynamics of their bilateral relations.

61 "Notice of the State Council on Issuing a New Generation Artificial Intelligence Development Plan." 